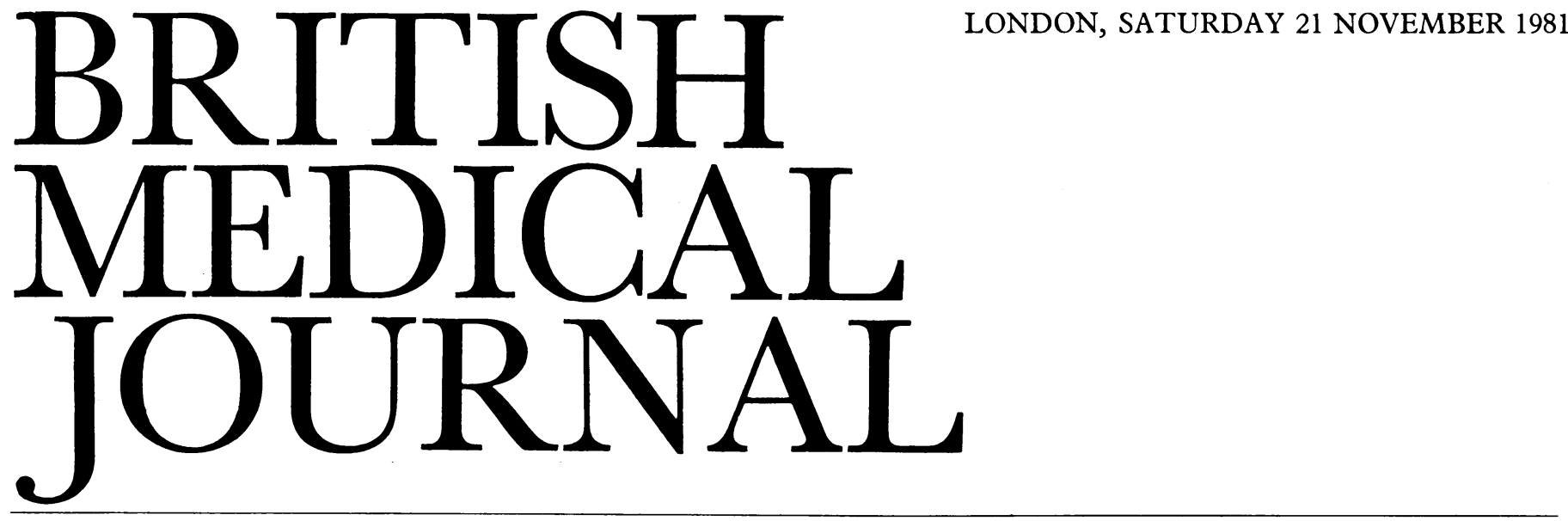

\title{
Subarachnoid haemorrhage
}

Subarachnoid haemorrhage is a more complicated illness than at first appears. The risk of recurrent haemorrhage has to be assessed against a background of widespread systemic events. It is the unpredictable relationship between these two factors which leads to the diversity of opinion on management. ${ }^{1}$

Bleeding into the subarachnoid space characteristically causes a sudden pain in the head, photophobia, and vomiting. The development of neck stiffness and the presence of Kernig's sign are evidence of blood in the subarachnoid space. In more severe cases blood may enter the substance of the brain and produce signs dependent on the function of the part damaged, when differentiation from primary cerebral haemorrhage may be difficult. Though $10-15^{\prime \prime}$ " of patients die as a result of the initial bleeding ${ }^{2}$ this is often mild, there is no immediate damage to the nervous system, and full recovery is possible. When haemorrhage recurs soon after the initial bleed nearly half the patients will die. The recognition of the mild case is therefore important if recurrent haemorrhage is to be prevented and the systemic effects controlled.

In one co-operative study ${ }^{3}$ based on 6368 patients $54^{\prime \prime}$ "had at least one aneurysm and $6^{\prime \prime}$ ", an arteriovenous malformation. In this study $22^{\prime \prime}$ " of the patients with an anterior circle aneurysm bled again in the first two weeks and $15^{\circ}$ " in the next two, but $11^{\circ}$ "of all rebleeding episodes occurred after a delay of over one year. ${ }^{2}$ Another multicentre investigation ${ }^{4}$ showed that only $52^{\circ}$ " of patients admitted in good condition were alive and well at three months, the group treated by operation being at a slight advantage.

Subarachnoid haemorrhage is the first symptom in about half of all patients with intracranial arteriovenous malformations, and $10^{\circ}{ }^{\circ}$ die as a direct result." While the risk of immediate recurrent haemorrhage is less than for aneurysm, the long-term outlook is poor. When a patient with an arteriovenous malformation presents with haemorrhage he has a one in four chance of further haemorrhage within four years. ${ }^{\circ}$

What, then, can be done to reduce the risk of early recurrent haemorrhage? Dissolution of the clot may be one important cause, and antifibrinolytic agents have been shown to reduce bleeding. With aminocaproic acid, however, the incidence of hydrocephalus is increased, ${ }^{7}$ and while tranexamic acid also reduces recurrent haemorrhage the incidence of cerebral ischaemia is increased. ${ }^{\times}$At best, the place of antifibrinolytic agents is uncertain. On the other hand, the obliteration of an aneurysm certainly will prevent recurrent haemorrhage, and this has encouraged surgeons to operate. During the past decade the introduction of microneurosurgical techniques and improvements in anaesthesia have made it possible for neurosurgeons to obliterate most aneurysms. None the less, a technically successful operation may be followed by morbidity and death. The explanation lies in the importance of the systemic effects which follow the entry of blood into the subarachnoid space and lead to ischaemia of the brain and other organs. The exact mechanism is obscure. Neil-Dwyer and his colleagues ${ }^{9}$ have shown abnormal activity of the autonomic nervous system after subarachnoid haemorrhage with areas of necrosis in the hypothalamus and heart. Possibly these changes might be prevented by adrenergic blockade. ${ }^{10}$ C H A Meyer et al, using a xenon rebreathing technique, showed in a paper presented to the Society of British Neurological Surgeons in Cardiff in 1980 that cerebral blood flow falls progressively during the first two to three weeks after the haemorrhage. In their patients this was a universal response, though variable in degree. The higher blood flow immediately after haemorrhage gives credence to the claim that early operation may be beneficial. Those who advocate early operation argue that the increased risk of surgery at this stage is more than offset by the reduced rate of recurrent hacmorrhage and the subsequent systemic effects, ${ }^{11}{ }^{12}$ but further studies are needed.

As a general conclusion, recurrent aneurysmal subarachnoid haemorrhage is preventable by surgical extirpation, but other factors must be considered. About $4 \%$ of patients have multiple aneurysms. Most surgeons would recommend obliteration of the aneurysm which has bled, if this can be identified clearly, and any other that is easily accessible at the same operation. In older patients subarachnoid haemorrhage usually reflects diffuse cerebrovascular disease, and morbidity of angiography and operation increases with age.

In favourable circumstances the risk of mortality and morbidity from surgical treatment is now less than $5 \%{ }_{0}^{13}-\mathrm{a}$ great improvement on the clinical course of a recently ruptured aneurysm. When the general effects of the haemorrhage are prominent, reflected in severe persistent headache, unstable blood pressure, fluctuating level of response, and neurological abnormalities, mortality and morbidity are very high and increased by operation. In these circumstances treatment should be delayed until the patient has fully recovered from the systemic effects of the haemorrhage. If this essential delay exceeds eight weeks many prefer (surgeons, physicians, and patients) to continue conservative treatment, for by that time 
the outcome of an expectant policy is not demonstrably different from the immediate risk of operation.

What is the future? Drug treatments may be found to reduce or prevent the harmful effects of abnormal adrenal activity and render operation safer. ${ }^{14}$ Antifibrinolytic agents may be found which do not increase the risk of communicating hydrocephalus and cerebral ischaemia. Their place is likely to be limited, however, because the primary fault remains untreated. Mechanical factors are important. An aneurysm is a highly stressed and unstable structure, whose wall differs from that of the parent vessel; varying in thickness, at places gossamer thin, at others tough and fibrous and sometimes calcified. These factors concentrate stress at particular points in the aneurysm wall. When the strain energy stored in the wall of the aneurysm is sufficient to fracture the aneurysm it either leaks or bursts explosively, depending on the prevailing conditions. Engineers and surgeons working together will certainly add to our understanding of the mechanisms concerned, even if this line of research initially has little impact on management (A D Harman, PhD thesis, University of Reading, January 1980). Finally, Pope et $a l^{15}$ have shown that over half the patients they investigated were deficient in type III collagen, raising the possibility of identifying people at special risk of subarachnoid haemorrhage.

J R BARTLETT

Consultant Neurosurgeon,

Brook General Hospital,

London SE18 4LW

1 Wilkins RH. Update-subarachnoid haemorrhage and saccular intracranial aneurysms. Surg Neurol 1981 ;15:92-101.

2 Locksley HB. Report on the Cooperative Study of Intracranial Aneurysms and Subarachnoid Hemorrhage, section V, part II. Natural history of subarachnoid hemorrhage, intracranial aneurysms and arteriovenous malformations. Based on 6368 cases in the cooperative study. $f$ Neurosurg 1966;25:321-68.

${ }^{3}$ Locksley HB. Report on the Cooperative Study of Intracranial Aneurysms and Subarachnoid Hemorrhage, section V, part I. Natural history of subarachnoid hemorrhage, intracranial aneurysms and arteriovenous malformations. Based on 6368 cases in the cooperative study. $y$ Neurosurg 1966;25:219-39.

* Adams HP, Kassell NE, Torner JC, Nibbelink DW, Sahs AL. Early management of aneurysmal subarachnoid hemorrhage. I Neurosurg $1981 ; 54: 141-5$.

${ }^{5}$ Perret G, Nishioka H. Report on the Cooperative Study of Intracranial Aneurysms and Subarachnoid Hemorrhage. Section VI. Arteriovenous malformations. An analysis of 545 cases of cranio-cerebral arteriovenous malformations and fistulae reported to the cooperative study. $\mathcal{F}$ Neurosurg $1966 ; 25: 467-90$.

${ }^{6}$ Forster DMC, Steiner L, Håkanson S. Arteriovenous malformations of the brain. A long-term clinical study. $\mathcal{F}$ Neurosurg 1972;37:562-70.

${ }^{7}$ Park BE. Spontaneous subarachnoid hemorrhage complicated by communication hydrocephalus: epsilon amino caproic acid as a possible predisposing factor. Surg Neurol $1979 ; 11: 73-80$

${ }^{8}$ Fodstad H, Forssell A, Liliequist B, Schannong M. Antifibrinolysis with tranexamic acid in aneurysmal subarachnoid hemorrhage : a consecutive controlled clinical trial. Neurosurgery 1981 ; 8:158-65.

${ }^{9}$ Neil-Dwyer G, Cruikshank J, Doshi B, Walter P. Systemic effects of subarachnoid haemorrhage. In: Wilkins $\mathrm{RH}$, ed. Cerebral arterial spasm: proceedings of the second international workshop. Baltimore: Williams and Wilkins, 1980:256-65.

${ }^{10}$ Doshi B, Neil-Dwyer G. Clinicopathological study of patients following a subarachnoid hemorrhage. I Neurosurg 1980;52:295-301.

11 Hori S, Suzuki J. Early intracranial operations for ruptured ancurysms. Acta Neurochir (Wien) 1979 ;46:93-104.

${ }^{12}$ Sano K, Saito I. Timing and indication of surgery for ruptured intracranial aneurysms with regard to cerebral vasospasm. Acta Neurochir (Wien) $1978 ; 41: 49-60$.

${ }^{13}$ Johnson RT. Surgery of cerebral haemorrhage. In: Brain Lord, Wilkinson $M$, eds. Recent advances in neurology and neuropsychiatry. 8th ed. Edinburgh: J A Churchill, 1969:102-28.

14 Walter P, Neil-Dwyer G, Parsons V. The effect of phentolamine and propranolol in subarachnoid haemorrhage. In : Wilkins RH, ed. Cerebral arterial spasm: proceedings of the second international workshop. Baltimore: Williams and Wilkins, 1980:584-8.

${ }_{15}$ Pope FM, Nicholls AC, Narcisi P, Bartlett J, Neil-Dwyer G, Doshi B. Some patients with cerebral aneurysms are deficient in type III collagen. Lancet $1981 ; \mathrm{i}: 973-5$.

\section{Charitable organisations in medical research}

The $\mathbf{1 3 5} 000$ or so charities in Britain range in size from those which spend millions of pounds each year to small funds often dedicated to meeting some limited local objective. A recent estimate $^{1}$ suggests that their total annual income is around $£ 2600 \mathrm{~m}$. Indirectly, considerable sums of public money are concerned, because of the tax concessions given to charities. The question may be asked whether the state or a public nongovernmental organisation could not use this money to better effect. The answer is probably no. Raising the necessary revenue by fiscal means would politically be very difficult, while individuals and corporate bodies would be unlikely to donate voluntarily to the state those sums of money which they currently give to the charities. Furthermore, the assumption of these activities by the government would also remove from donors the freedom to express most directly their individual views on priorities for the improvement of society. The trustees and administrators of charities therefore have a responsibility to show that their money is used to best advantage.

The total number of charities which include medicine and medical research among their activities is uncertain, but most of the larger ones are among the $\mathbf{3 5}$ members of the Association of Medical Research Charities, which in 1980 spent about $£ 85 \mathrm{~m}$ on medical care and research-and of this sum $£ 55 \mathrm{~m}$ was spent on research. Some large organisations which are not members of the association and very many smaller charities make important contributions to research at a local level; so the total provided by charities for medical research is certainly much higher than $£ 55 \mathrm{~m}$. The Medical Research Council, by comparison, spent $£ 81 \mathrm{~m}^{*}$ on medical research during $1980 . .^{2}$

There are major differences in the ways in which the charities and the Medical Research Council use their funds. Most important, the Medical Research Council presently supports 60 research establishments (including the National Institute for Medical Research and the Clinical Research Centre) which account for $58 \%$ of its funds, leaving $42 \%$ available for shorterterm research commitments. ${ }^{2} 3$ The charities, by contrast, are the sole or principal supporters of 26 institutions or units, accounting for $41 \%$ of their funds, leaving $59 \%$ for other activities. As a result, in 1980 the Association of Medical Research Charities was able to make 967 new project grants and continue support for another 2004, whereas the Medical Research Council made 506 new project grants and continued 1082. Similarly, the Association of Medical Research Charities was supporting 257 programmes against the Medical Research Council's 158. The Medical Research Council, however, provided more personal support grants-1881 against 1160 by the Association of Medical Research Charities. The difference in the number of short-term projects supported is, however, much greater than would be expected from a straightforward consideration of the sums of money available. The figure for the total number of grants made by the charities includes a substantial number of project grants for periods of one to two years (by comparison with the standard three-year period for the Medical Research Council), and these contribute considerably to the total. These short-term grants serve two main purposes: they provide funds for clearly defined projects of limited duration and they also provide seed money which

*The Medical Research Council year runs from 1 April to 31 March. This figure is derived by adding $25^{\circ}$, of the expenditure for $1979-80$ to $75^{\prime \prime}$, of the expenditure for $1980-1$. 